\title{
Articles
}

\section{A Collaborative approach to implementing $21^{\text {st }}$ Century skills in a High school senior research class \\ By Michael K. O’Sullivan and Kim B. Dallas}

\begin{abstract}
Businesses and higher education leaders are looking for students with the ability to evaluate and analyze information and to use this information to solve real-world problems. These are the information literacy skills students need for the $21^{\text {st }}$ century. However, several recent studies on the ability of college freshmen to handle the rigor of college courses and research indicate that high school students are not being adequately prepared to apply these skills. The authors provide a case study of a collaborative effort between an English teacher and the high school librarian to better prepare high school seniors on how to locate reliable information, analyze the information and then determine how it can be applied to solving a real world issue or problem.
\end{abstract}

\section{Introduction}

The goal of any high school is to ensure that its students have the knowledge and skills they need to be successful in college and in the workplace. However, several recent studies have claimed high school students are graduating without the necessary basic skills they need to be successful in college or at work. High schools throughout the country are being pushed to redesign and align their curriculum with college readiness standards. The problem is that there is no consensus among postsecondary institutions as to what constitutes “readiness”, and "readiness” may vary from institution to institution (Olson, 2006, April 26). This article will focus on how a high school research paper class, as an example, can be designed and structured to give high school seniors an opportunity to experience what college level research and writing involves.

A study conducted by ACT, Inc., entitled "Rigor at Risk: Reaffirming Quality in the High School Core Curriculum" (2007), states that to eliminate the essential skills gap between secondary and postsecondary education needed to be successful in college, high school courses should be made more rigorous. Many of these studies have focused on the basic reading, writing and math skills needed for college entry. However, simply requiring high school students to take more years of math, science and language arts will not ensure their success in meeting the rigorous academic requirements of college or the workplace.

The Partnership for $21^{\text {st }}$ Century Skills, which includes the business community, education leaders and organizations, believes high school graduates must obtain strong learning skills in information gathering, communication, critical thinking and problem solving (Jobs for the Future, 2005). High school students need to be taught these sophisticated "higher-order" skills, such as the ability to locate and analyze complex information in order to solve real world problems.

For high school students to obtain these "higher-order" skills, the Partnership's agenda calls for high schools to align their graduation requirements "with college and workplace entrance expectations” (Jobs for the Future, p. 12). An earlier report from the National Commission on the High School Senior Year recommended a similar strategy through the creation of $\mathrm{K}-16$ councils in every state in order to strengthen relationships between high schools and two and four year institutions (Woodrow Wilson, 2001). Perhaps one of the reasons for the skills gap between high school and college is the fact that student standards are established in separate orbits. K-16 faculty members rarely work together on standards, curricula or assessment (Callan \& Kirst, 2008).

Other studies also include critical thinking and research skills into their definition of college readiness skills. These studies have found that high school students are not being adequately prepared for the rigors of a college research assignment. In a 2002 report, the Association of American Colleges and Universities gave a concise summary of the problem (Hammond, 2008, May 2), 
"Many colleges and universities have begun to encourage more in-depth, investigative, or research-based learning even in the first year, but high school and many AP courses continue to feature broad surveys and superficial 'coverage.' The senior year of high school, which ideally should emphasize the intellectual skills expected in college, is wasted for many students” (para. 5).

Another such study conducted by the Educational Testing Service (Foster, 2007) found that "college students and high school students preparing to enter college are sorely lacking in the skills needed to retrieve, analyze, and communicate information available online." ETS, with the assistance of seven large university systems, developed an iSkills assessment tool to measure both college and high school students' Information and Communication Technology (ICT) literacy performance (Katz, 2007). This assessment was designed to measure the students' problem-solving skills by using technology. Various colleges have used this assessment to determine their students' level of information and communication literacy skills.

But it is not sufficient to just measure the college students' ICT literacy skills. Research has shown that one of the major reasons why students falter in college is that college courses are fundamentally different than high school classes. College instructors expect students to solve complex problems that do not have obvious answers, conduct research, draw conclusions and find evidence to support their arguments (Conley, 2007, p. 24). Integrating information literacy skills into the college curriculum apparently is as problematic as it is in high school.

While information literacy is seen as an essential component of higher education, it is unclear where it fits in the university curriculum (Quarton, 2003). Practically speaking this should not be an issue, because information literacy skills can and should be integrated through course work at both the high school and college level in all disciplines. To support this concept of integration, the Partnership for $21^{\text {st }}$ Century Skills has developed a framework to help states, districts and schools integrate the core subject areas with $21^{\text {st }}$ century skills (Silva, 2008).

The findings of each of these subsequent studies reinforce what the National Commission on the High School Senior Year stated in 2001. In that report, entitled "Raising Our Sights: No High School Senior
Left Behind," the commission emphasizes both public and private high schools should be providing students with more rigorous and academically challenging curriculum (Woodrow Wilson, 2001). The report even spells out several of the same skills that the Partnership for $21^{\text {st }}$ Century Skills have identified as being critical for high school seniors to obtain. For example, the commission states that "high schools should be graduating students who are...capable of thinking critically and comfortable with...the problem-solving process (p. 10-11)." Students also should be able to connect key ideas between the sciences, history and society (p.13).

For high school seniors to be better prepared to handle the rigor and demands of a college research project, they should be exposed to classes in high school that require the application and use of specialized research skills and tools. According to Conley (2005), research projects should become a more central part of the high school curriculum in English as well as other subject areas. Conley adds that these research projects should progress from the "relatively simple" to the more complex throughout the four years of high school. He advocates for students to receive extensive experience writing many five to ten-page papers over four years (p. 83).

According to Gordon (2002), students "in K-12 are trapped in a reporting mode (p. 19).” High school research projects, when assigned, frequently center on reports, where students are required to read and summarize their findings into a four to five page paper. With the implementation of No Child Left Behind (NCLB) legislation, most high school curriculums have abandoned inquiry-based projects that challenge students to apply the knowledge they obtain through research, to solve or propose a solution to a real world problem. There is a difference between the skills needed to research and write a report and the skills required to research and write an analytical paper that actually applies the knowledge a student obtains to a specific social problem or issue.

One such class that can be offered at the high school level, which serves as a perfect vehicle in which to incorporate many of the $21^{\text {st }}$ century skills, including information literacy, critical thinking and problem solving, is a research paper class for high school seniors. Such a class has been offered to seniors at Rosemount High School, a suburban high school in the Twin Cities, for the past 20 years. The entire content of this class is designed around a single research paper, and is designed to emulate the demands of a college 
research assignment. The class has proven to be demanding, rigorous but fair, and at times overwhelming for some high school seniors.

This class is not just about writing a longer research paper (10 to 15 pages). The intent of this class is to introduce high school seniors to what it is like to research a subject in depth, to formulate research questions and develop curiosities that go beyond the basic facts of a topic. By breaking the research paper process into a series of steps with individual, specific due dates, the teacher has been able to stress the importance of time management and developing effective work habits. These skills, in addition to the research skills involved, are critical for seniors as they prepare to make the transition to college.

\section{The Research Paper Class}

When the Research Paper class was originally offered to seniors, the students were taught the basics of writing a research paper including how to select a topic, write a thesis statement, organize and find sources and finally how to put it all into a 10-15 page research paper. The role of the teacher librarian at this point was simply to take a couple of class periods to introduce students to the online catalog and research databases. However, just introducing the students to the library's resources was not adequate enough preparation for college level research.

In spite of this instruction and receiving library instruction in middle school, and again introduced to additional skills as ninth graders, the high school seniors quickly abandoned these skills and resources and reverted back to what they thought worked. They jumped back into Google, Yahoo or some other random search engine, entered a question or phrase and fully expected the answers to appear. Not surprisingly, they quickly became frustrated. In most cases they found too much information, and in others, not enough relevant or reliable information. It became apparent they had very little, if any, critical research skills.

The high school seniors in this class are no different than any other high school senior or college student, for that matter, across the country. While most high schools won't have a wide variety of information resources, both online or in print, that is not the case with college and university libraries. College libraries frequently have outstanding information resources available to their students - from subject encyclopedias, online catalogs and subscription databases, but many college students are either unaware of these resources or they do not know how to use them (Quarton, 2003). Quarton states, “...college students lacking these information skills are ill prepared to function in a technological and information-rich environment (p. 120).”

\section{Integrating the Teacher Librarian}

To determine exactly what research skills to incorporate and emphasize, the research paper teacher worked with the teacher librarian to revamp the curriculum for the class incorporating more intensive units involving library research skills as well as writing skills. As an example of true collaboration, the media specialist has become a co-teacher with the English teacher during the topic selection and research portion of the class.

As a result, the students' information literacy skills have moved beyond the basic keyword and natural language approach in which they have been indoctrinated by the various Internet search engines. Since then, the research paper class has been enhanced by emphasizing two distinct skill sets-information literacy and research writing, both of which are critical for these students in preparing them for college. In addition, these students begin to realize there is a systematic approach to doing research that will result in writing a successful academic-level research paper.

Minnesota high school students are fortunate to have access to a vast array of online research databases, including several academic level databases. Minnesota as well as several other states frequently contract with various vendors to provide access to a wide variety of online research databases. With resources like these, Rosemount High School students can easily simulate the college level research experience in their suburban high school media center.

Including the school's teacher librarian in the instructional process helps the students get started on the right foot with doing a research paper. In order to effectively incorporate the teacher librarian into a research paper class, it is important that he/she is introduced on the first day of class. In this situation, the librarian gives a brief overview of his background and how he will assist in orienting students to college level research skills. The teacher librarian conducts mini-lessons, lectures and administers exercises focusing on specific information literacy skills aligned with the Association of College and Research Libraries (ACRL) information literacy standards. 


\section{Step One: Selecting a topic}

Topic selection is where each research paper class begins. At first students feel this should be an easy step, because they often do not know the difference between a suitable research paper topic and a report topic. Most high school students, when faced with the task of selecting a topic for research, will opt for the easy out by selecting one of the many tried and true high school topics. The research paper teacher and the librarian work together to help students brainstorm, narrow down ideas, expose them to controversial issues and put some limitations on acceptable topics. To get them started, topics from previous classes are shared, current events are discussed, and a variety of subject specific encyclopedias are provided as sources of potential topic ideas.

Students are given nearly two weeks to select a research topic in which they are really interested. Giving them more time to explore topic ideas also helps them get past the 'brain freeze', many students experience when trying to select a topic for a major research paper. They are encouraged to tune into news broadcasts, such as BBC News America, to get a broader perspective of world events, to scan topic ideas from online databases, such as Opposing Viewpoints or Global Issues in Context, to read the headlines in the daily newspaper, to talk to teachers or parents, or to scan the "List of Entries" in the front of a subject encyclopedia to come up with topic ideas.

As students mine these resources, they are reminded that the course requires them to write about a topic that is relevant to society or has an impact on society, and which may involve a controversial issue. These types of topics require analytical thinking and problemsolving. Students are encouraged to approach their topics with an open mind and to select a topic they are truly interested in exploring.

By providing students more time to explore and think about a greater variety of issues, the quality and perspective on topics chosen has improved. When students select a topic they are truly interested in, the quality of their research and their writing improves dramatically. The class is structured to encourage students to consider their topic in context with history and society and to seek a deeper conceptual understanding of the issues surrounding or connected to their topic. This frequently results in students becoming aware that their topic impacts or is connected to other disciplines. To accomplish this skill, students participate in a series of brainstorming exercises.

\section{Step Two: Concept mapping}

During these exercises, students are encouraged to take their initial topic idea and explore any and all aspects or ideas related to their broader topic, no matter how remote the connection might be. To help the students connect ideas to other related ideas or subtopics, they fill out a concept map or use a software program, called Inspiration 8, to create their own web map. Concept mapping is a brainstorming technique that helps create a visual image or diagram of a topic and how it connects with other ideas or concepts. Using this technique, students often discover even more interesting topic ideas than what they originally had. It enables them to visualize their idea and see connections or relationships between seemingly unrelated concepts.

A second part to the concept mapping exercise asks students to select one of the related topics from their brainstorming map that piques their interest as a potential area of inquiry or research. To complete this concept map refocusing, students may need to do some preliminary research, using a subject encyclopedia article, to obtain background information on their topic. The purpose of the refocusing exercise is to help students narrow the focus of their topic by examining the economic, social or environmental implications of their topic. They will contemplate specific causes, solutions, effects and/or benefits related to their main topic, as well as any people, places or things directly associated with or related to the topic. This aspect of the concept mapping exercise helps them gain a deeper conceptual understanding of their topic, which is considered one of the competencies required for the $21^{\text {st }}$ Century (Silva, 2008). This refocusing exercise also helps them formulate effective research questions. For an example of a completed concept map and topic refocusing, click here http://www.district196.org/rhs/library/Documents/Con cept $\% 20$ MapExample.pdf

\section{Step Three: Formulating a Research Question}

The ability to formulate an effective research question that addresses the causes, effects or solutions related to their topic, helps the students focus their ideas and points them in the right direction to begin their research. Students are asked to develop several research questions to re-frame their topic in a variety of different ways in order to narrow their topic even more. Teaching students to come up with an effective research question, using question words like what, why or how, is a fundamental step in the research process and encourages students to critically analyze all elements of their topic. 
A well developed research question also helps them formulate a working thesis statement that succinctly summarizes their main idea, position and solution to their topic. In order to develop a good research question, the students must have a clear understanding of what issues are relevant to their topic and what types of questions have been explored in relation to their topic. Once the research question is formed, students easily move onto the next step of finding and identifying keywords.

\section{Step Four: Keywords vs. Subject Headings}

Once a student settles on one of their research questions, they are instructed on how to identify the keywords or key concepts incorporated in their questions. For example:

\section{What benefits can an urban mass transit system provide in revitalizing economic development and growth in today's U.S. metropolitan areas?}

Using the keywords/search terms from their research question, the teacher librarian stresses the importance of developing a comprehensive, dynamic list of related keywords or synonyms, and in identifying the appropriate subject headings for the key concepts in their research question. Using the Library of Congress' catalog, WorldCat or a university level catalog, students are expected to identify the Library of Congress (LC) subject headings that are used to categorize issues dealing with or related to their topic. The students also receive instruction on the difference between a keyword and subject heading search and how to apply these approaches to improve their search results. An example of a completed keyword/subject heading exercise: http://www.district196.org/rhs/library/Documents/Wo men in military keyword exercise.doc

\section{Step Five: Developing a Search Strategy}

The next component in the research process introduces the high school students to the world of college level research. They are introduced to college level resources and receive instruction on how to employ various search strategies in order to improve the relevancy of their search results. The students are instructed on how to apply their keywords and/or subject headings using various research databases to which the library subscribes or has access to, including Academic Search Premier, Expanded Academic, Health and Wellness Resource Center, ERIC, Opposing Viewpoints, LexisNexis and Science Resource Center. A list of the library's online resources is available at http://www.district196.org/rhs/library/database.html. All of these databases allow remote access, so students can do research at home or at other off-campus sites.

The students learn the difference between popular and scholarly articles, how to locate and identify scholarly sources, as well as the resource trail a scholarly article will provide them. To become acclimated to the world of "academic" research, the students are required to include at least three scholarly articles in their works cited page. Students are shown how the results from these subscription databases differ from the results obtained from an Internet search using Google or some other search engine. If they choose to include information from a random internet search, an online internet evaluation form must be completed to verify the reliability of the information provided at the website.

http://www.district196.org/rhs/library/webevaluation.cfm.

In order to use the databases more effectively to locate relevant information, students are taught how to apply more advanced, college related research skills from the use of Boolean operators to help narrow or broaden their search results, to applying limiters to their search or employing truncation in order to retrieve related articles. They also are shown how to take advantage of such database features as creating a research folder to save their articles, marking and e-mailing their results home, downloading or saving their marked articles under favorites and how to properly cite their sources in MLA format. The students use NoodleTools, a note taking and bibliographic citation program.

These high school seniors also learn about the valuable service, librarians can provide through interlibrary loan. They quickly learn that not everything is full text online or through Google, and are encouraged to submit book and journal article requests to the teacher librarian. Using a statewide service, entitled Minitex, provided by the Minnesota Office of Higher Education and the University of Minnesota, the teacher librarian is able to pretty much fulfill any interlibrary loan request from a journal article to an academic book.

\section{Step Six: Writing the Research Paper}

As students begin the transition from the research to the writing phase, the research paper teacher has established various benchmarks to help the high school students stay on task and on schedule. At various stages in the research and writing process, deadlines and points are assigned to different phases in the process. Students are expected to submit documentation of their research, a copy of their thesis 
statement which clearly states their problem and how they plan to resolve it. Other benchmarks students are expected to meet include an annotated bibliography following the MLA style guide, note cards using NoodleTools, an online bibliographic and note taking program, rough drafts of the first five pages, followed by drafts of their paper for peer review. As a final assessment, each student is expected to orally present their thesis along with a summary of their research findings explaining how they supported their thesis. By structuring the class in this manner, the research paper teacher effectively demonstrates the importance of establishing and following a schedule when undertaking a major research paper assignment at the college level.

Students are required to use a variety of sources in their works cited page, including subject specific books, scholarly articles and government documents in addition to the more popular resources they obtain from the newspaper and periodical databases at their disposal. By making this a required and graded part of the course, students are exposed to higher reading and vocabulary levels that require critical thinking and analytical skills.

\section{Step Seven: Assessment}

Likewise, at various points in the class, the teacher and the librarian will administer specific information literacy assessments using the online assessment tool, Trails9.org. The specific skill assessments, that have been used with the high school seniors, have included the identification of potential sources, the ability to develop, use and revise search strategies and the ability to evaluate sources and information. These online assessments are administered several weeks after the students have completed a part of their research. Before the students log into Trails9.org, the librarian will conduct a short review of the basic elements that comprise the particular skill area being tested.

The teacher and the librarian have used the results of these assessments to not only determine if the high school seniors fully comprehend the concepts and skills involved in these aspects of the research process, but also to evaluate, revise and improve the instructional components related to the specific information literacy skills.

To further assist the students in the research and writing process, the teacher and teacher librarian developed an online Research and Writing Center Page that incorporates examples and tips on various aspects of the research process, as well as advice and examples for the writing process. The Research and Writing Center page

$<$ http://www.district196.org/rhs/library/ReswritingCent er.htm> was patterned after several prominent College and University online Writing Centers.

\section{Conclusion}

By integrating more advanced research skills into the core curriculum of a research paper class, high school students will be better prepared to handle the stress and rigor of a college research assignment. This class incorporates the essence of $21^{\text {st }}$ century skills, by enabling students to apply and use the knowledge they obtain about a certain topic in order to propose a possible solution to a real world problem or issue (Silva, date, p. 2).

The research paper class at Rosemount High School has been structured to incorporate college level research skills with the writing elements required for a college level research paper. By structuring the course with these two elements, students have reported they feel less intimidated by the idea of doing college research and/or including a research librarian in the research process.

Several students, who have gone on to a four-year college or university, have reported they not only scored well on their first major college research paper, but they also had very little trouble navigating and using their college library's resources. One former student reported, "Everything we learned was huge. Some kids never get this information before they get to college and they had a ton of trouble."

This class provides a perfect opportunity for the research paper teacher and the high school librarian to collaborate in developing a class that prepares students for the rigor of college and the world of work in the $21^{\text {st }}$ century. 


\section{References}

ACT, Inc. (2007). Rigor at risk: Reaffirming quality in the high school core curriculum. Iowa City, IA: ACT, Inc. (ERIC Document Reproduction Service No. ED496670)

Callan, P. M., \& Kirst, M. W. (2008, June 8). Righting a troublesome 'Disjuncture': A push-pull strategy for P-16 cooperation. Education Week. 27(40), 22-25. Retrieved August 13, 2009, from Education Full Text database.

Conley, D. T. (2007). The challenge of college readiness. Educational Leadership. 64 (7), 2329. Retrieved January 22, 2008, from Academic Search Premier.

Conley, D. T. (2005). College Knowledge: What it really takes for students to succeed and what we can do to get them ready. San Francisco: Jossey-Bass.

Foster, A. L. (2007). Students fall short on 'information literacy,' Educational Testing Service's Study finds. Chronicle of Higher Education. 53(10), A36. Retrieved January 10, 2008, from Academic Search Premier.

Gordon, C. A. (2002). A eoom with a view: Looking at school library instruction from a higher education perspective. Knowledge Quest. 30(4), 16. Retrieved January 22, 2008, from WilsonWeb Education FullText.

Hammond, B. G. (2008). Advancing beyond AP courses. Chronicle of Higher Education. 54(34), B17. Retrieved May 1, 2008, from $<$ http://www.chronicle.com $>$.

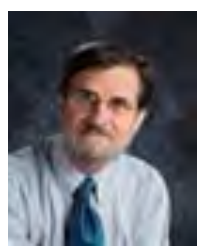

Michael K. O’Sullivan michael.osullivan@district196.org

Rosemount High School $3335142^{\text {nd }}$ Street West Rosemount, MN 55068
Harney, J. O. (2006). Ready yet? Connection. 20(4), 5. Retrieved January 10, 2008 from Academic Search Premier.

Jobs for the Future. (2005). Education and skills for the $21^{\text {st }}$ Century: An agenda for action. Boston, MA: Jobs for the Future.

Katz, I. R. (2007). Thinking beyond technology: using the iSkills assessment as evidence to support institutional ICT literacy initiatives. Knowledge Quest. 35(5), 36. Retrieved July 30, 2009, from Academic OneFile.

Olson, L. (2006). Views differ on defining college prep. Education Week. 25(33), 1-29. Retrieved January 10, 2008, from MasterFILE Premier.

Quarton, B. (2003). Research skills and the new undergraduate. Journal of Instructional Psychology. 30(2), 120. Retrieved June 7, 2008, from Academic OneFile.

Silva, E. (2008, December). Measuring skills for the $21^{\text {st }}$ century. Education sector reports. Education sector. Retrieved May 2, 2009, from ERIC.

Woodrow Wilson National Fellowship Foundation. (2001). Raising our sights: No high school senior left behind. Final report, national commission on the high school senior year. Princeton, NJ: Senior Year Report, the Woodrow Wilson National Fellowship Foundation. Retrieved August 6, 2009, from ERIC.

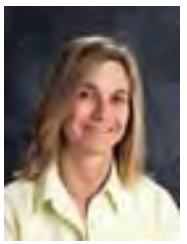

Kim B. Dallas

kim.dallas@district196.org 